\title{
Clinical competencies of physical therapy interns in patients' management skills
}

\author{
Anum Tariq ${ }^{1}$, Muhammad Kashif ${ }^{2}$, Mahat Zafar ${ }^{3}$, Sana Hanif ${ }^{4}$, Irum Ali $^{5}$, Ammar Shafique $^{6}$
}

\section{Submitted:}

October 12, 2020

Accepted:

December 3, 2020

\section{Author Information}

${ }^{1}$ Akhtar Saeed

Medical and Dental College Lahore, Pakistan

${ }^{2,3}$ Riphah College of Rehabilitation \& Allied Health

Sciences, Riphah International University, Pakistan

${ }^{4,5}$ School of Rehabilitation Sciences,

The University of Faisalabad Pakistan

${ }^{6}$ Abwa Medical College, Faisalabad Pakistan

\section{Corresponding Author}

Muhammad Kashif

Riphah College of Rehabilitation and

Allied Health Sciences,

Riphah International University, Faisalabad

Email: kashif.shaffi@gmail.com

\begin{abstract}
Introduction: Graduates of physiotherapy educational and training programs should be expected to work as a competent clinician. Studies carried out in different parts of the world show contradicting results. This study was designed to evaluate the competencies of physical therapy interns in patients' management skills. Material \& Methods: A cross-sectional study was carried out from July, 2019 to December, 2019 on fiftytwo physical therapy interns who were working in different clinical settings. The sampling technique used for this survey was purposive sampling. Twenty clinical physical therapists assessed competencies of these interns using the modified version of Clinical Internship Evaluation Tool. SPSS version 20 was used for data analysis.

Results: Clinical physiotherapists who assessed the competencies of the physiotherapy interns stated that the proficiency of all $(n=52,100)$ participants in relation to patients management skills was satisfactory for their current educational level. Thirteen $(25 \%)$ of the respondents had thinking that examination is an area of concern and more than a half $(53.8 \%, \mathrm{n}=28)$ mentioned that examination is an area of strength and $21.2 \%$ $(n=11)$ of them gave no response about examination. Questions related to examination revealed that majority $(n=45,86.5 \%)$ respondents think that they obtain accurate history. Similarly, majority ( $n=47$, $90.4 \%$ ) of participants responded that they determine diagnosis for physical therapy management of the patients. On a scale from 0 to 10 , the interns were compared to a competent clinician who is able to skillfully manage patients in an efficient manner to achieve effective patient/client outcome. About $44.2 \%(n=23)$ of the respondents gave 4 out of 10 rating, $51.9 \%(n=27)$ of them gave 5 number and $3.8(n=2)$ of them were awarded 6/10 number of clinical competences.

Conclusion: We concluded from the study that almost all the physical therapy interns were competent in regards to in-patients management skills.

Key Words: Competence, clinical, physical therapy interns, patients management skills.
\end{abstract}

The authors declared no conflict of interest and agreed to be accountable for all aspects of the work in ensuring that questions related to the accuracy or integrity of any part of the work are appropriately investigated and resolved.All authors contributed substantially to the planning of research, questionnaire design, data collection, data analysis and write-up of the article

This article may be cited as: Tariq A, Kashif M, Zafar M, Hanif S, Ali I, Shafique A. Clinical competencies of physical therapy interns in patients management skills. Reh J Health Sci. 2020;2(2). 52-55

\section{INTRODUCTION}

Despite the fact that rehabilitation medicine is an important pillar of modern medicine yet physiotherapy has not received much attention in past. ${ }^{1,2}$ Although there seems much focus on physical therapy treatment along with pharmacological treatments in some area of the world. ${ }^{3}$ Physical therapy students, interns and clinicians should be capable of proper assessment, diagnosis and treatment. ${ }^{4}$ The suggestions from the Institute of Medicine emphasize on the need for clinical training programs so that the new graduates will have five very important skills that included the care directed to the patients, interdisciplinary team approach, and practice based on evidence and ensuring quality services. ${ }^{5}$ Moreover, the World Confederation of Physical Therapy guidelines recommend that competent physical therapists should have the following four basic patient management skills: examination, assessment, diagnosis and prognosis at bachelor level degree. ${ }^{6}$

In 2001 \& 2002, the students of university of South Carolina were selected and were checked on the basis of their clinical competency by using a test which is called clinical skills step two. In the test the students were asked to manage a specified group of patients. The competency of them was based on their groups and their test scores. Both of them were the most important factors in the study determining skilfulness, however, the future of the students did not depend much on the scores obtained in the test compared to predicted eligibility. ${ }^{7}$ Although there are several tools for assessing the competence of PT's trainees, the Clinical Instruments Evolution Tool is designed to compare the performance of trainees with a higher benchmark, namely the level of competent PT., Due to increasing number of physiotherapy colleges in Pakistan, a huge number of new physiotherapy graduates have tremendously increased in the last decade. ${ }^{10}$ Higher Education Pakistan has introduced that all academic physiotherapy programs require the completion of a mandatory 1-year clinical practice Internship. ${ }^{11}$ During internship, physical therapy interns are involved in assessment, diagnosis and management of patients. Because these interns are in direct contact with patients, it is necessary that they should have reasonable competency level in patients management skills. To the authors' knowledge, there is no study present which reported competencies of physical therapy interns in Pakistan. Therefore, 
this study was designed to report the competency of physical therapy interns in patients management skills in Pakistan.

\section{MATERIALS \& METHODS}

A cross sectional study was conducted from July 2019 to December 2019. Fifty-two final year physical therapy students who were working as physical therapy interns in different clinical settings included Faisalabad, Lahore, Ghurki and Kharian, were selected for study through purposive sampling. Twenty clinical physical therapists assessed competencies of these interns using the modified version of Clinical Internship Evaluation Tool. Clinical Internship Evaluation Tool is the tool that is used for the assessment of physical therapy interns' performances and competencies. The tool is developed by professionals working in the University of Pittsburgh. This tool has two parts: the first part covers the professional attitudes i.e. Safety, ethics, initiative, and communication skills. The other part assesses the interns' performances and covers the sections of examinations, evaluations, diagnosis/prognosis and interventions. ${ }^{9}$ Data collected was entered and analyzed through SPSS version 20.

Results were displayed through charts and tables wherever and as needed.

\section{RESULTS}

Twenty (15 female and 5 male) clinical physical therapists assessed the competencies of 52 physical therapy interns. Majority of these physical therapists had 6-10 years' experience (table 1). All of the included interns' levels of competency of in-patient management skills were reported as 'satisfactory for their current level of education'. Thirteen (25\%) of the respondents was of the view that that the current examination was one of their areas of concerns, while more than a half $(53.8 \%, \mathrm{n}=28)$ mentioned that examination is an area of strength. A total of 11 participants (21.2\%) gave no response about examination (Table 2). Questions related to examination revealed that majority $(\mathrm{n}=45,86.5 \%)$ respondents think that they obtain accurate history (Table 3). Similarly, majority ( $n=47,90.4 \%$ ) of participants responded that they determined diagnosis for physical therapy management of the patient (Table 4). On a scale from 0 to 10 , the interns were compared to a competent clinician who were able to skillfully manage patients in an efficient manner to achieve effective patient/client outcomes. About $44.2 \%(n=23)$ of the respondents gave 4 out of 10 rating, $51.9 \%(n=27)$ of them gave 5 out of 10 rating and $3.8 \%(n=2)$ of them were awarded 6 out of 10 rating for clinical competence.
Table 1: Characteristics of

Clinical Physical therapists (PTs) Assessor

\begin{tabular}{|c|c|c|}
\hline Variables & Frequency & Percentage \\
\hline \multicolumn{3}{|l|}{ Gender } \\
\hline Male & 5 & $25 \%$ \\
\hline Female & 15 & $75 \%$ \\
\hline \multicolumn{3}{|l|}{ Age(years) } \\
\hline $21-29$ & 6 & $30 \%$ \\
\hline $30-40$ & 9 & $45 \%$ \\
\hline$>40$ & 5 & $25 \%$ \\
\hline \multicolumn{3}{|l|}{ Experience (years) } \\
\hline $1-5$ & 6 & $30 \%$ \\
\hline $6-10$ & 9 & $45 \%$ \\
\hline$>10$ & 5 & $25 \%$ \\
\hline \multicolumn{3}{|l|}{ Qualifications } \\
\hline BSPT & 2 & $10 \%$ \\
\hline DPT & 9 & $45 \%$ \\
\hline Master's & 9 & $45 \%$ \\
\hline $\mathrm{PhD}$ & 0 & $0 \%$ \\
\hline \multicolumn{3}{|l|}{ Employment } \\
\hline Government Sector & 11 & $55 \%$ \\
\hline Private Sector & 9 & $45 \%$ \\
\hline \multicolumn{3}{|l|}{ City } \\
\hline Faisalabad & 10 & $50 \%$ \\
\hline Lahore & 8 & $40 \%$ \\
\hline Ghurki & 1 & $5 \%$ \\
\hline Kharian & 1 & $5 \%$ \\
\hline
\end{tabular}

Table 2: Respondents' perception about area of concern and area of strength

\begin{tabular}{lllllllll}
\hline Response & \multicolumn{2}{l}{ Examination } & \multicolumn{2}{l}{ Evaluation } & \multicolumn{2}{l}{ Diag/ Prog } & \multicolumn{2}{c}{ Intervention } \\
& Freq. & $\%$ & Freq. & $\%$ & Freq. & $\%$ & Freq. & $\%$ \\
\hline Area of concern & 13 & 25.0 & 26 & 50.0 & 30 & 57.7 & 6 & 11.5 \\
Area of strength & 28 & 53.8 & 5 & 9.6 & 11 & 21.2 & 10 & 19.2 \\
No response & 11 & 21.2 & 21 & 40.4 & 11 & 21.2 & 36 & 69.2 \\
Total & 52 & 100.0 & 52 & 100.0 & 52 & 100.0 & 52 & 100.0 \\
\hline
\end{tabular}




\section{Questions related to Examination}

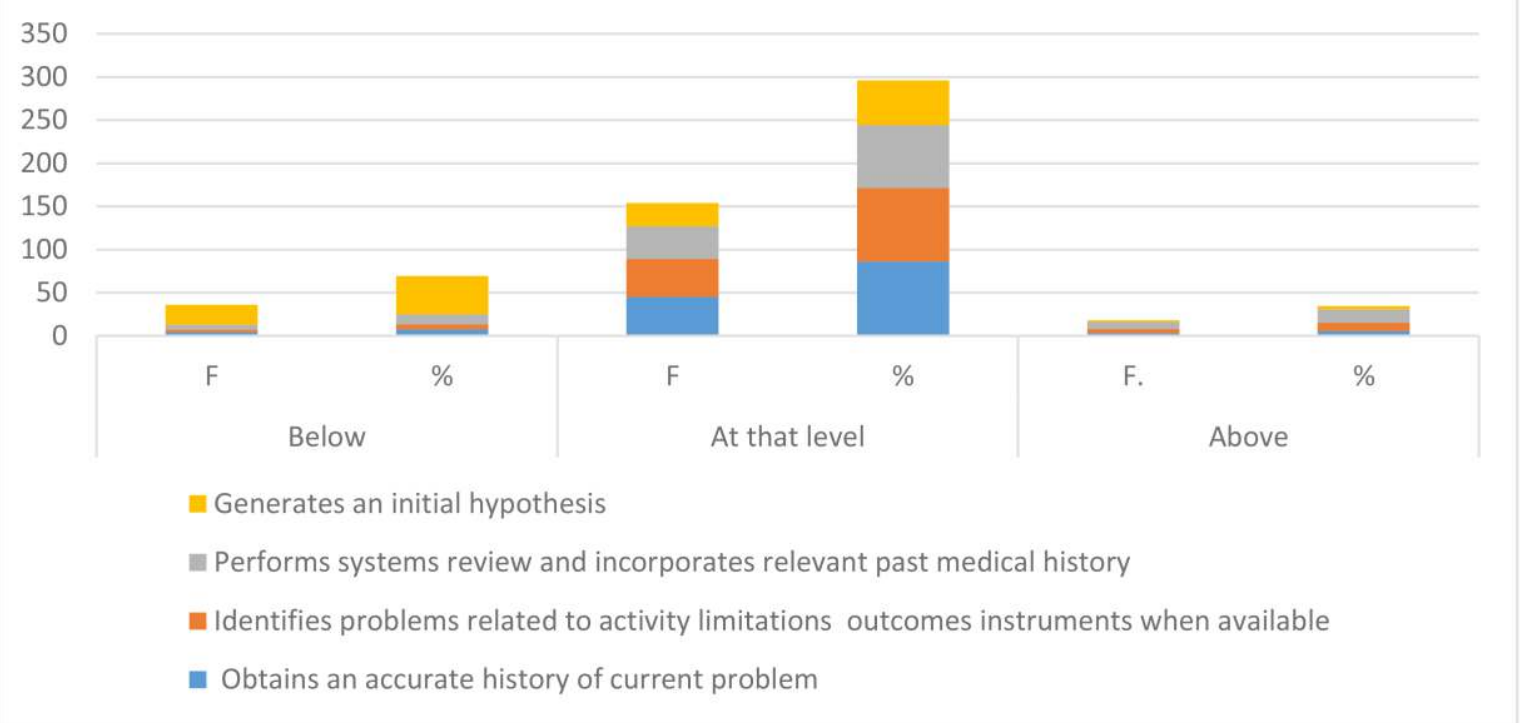

Figure I: Questions related to examination

\section{Questions related to diagnosis and prognosis}

5. Determines criteria for discharge

4. Determines appropriate duration and frequency of intervention; considers cost effectiveness

3. Selects appropriate physical therapy interventions or makes appropriate consultations or referrals

2. Determines expected outcomes (using standardized indices of activity limitations and participation...

1. Determines a diagnosis for physical therapy management of the patient

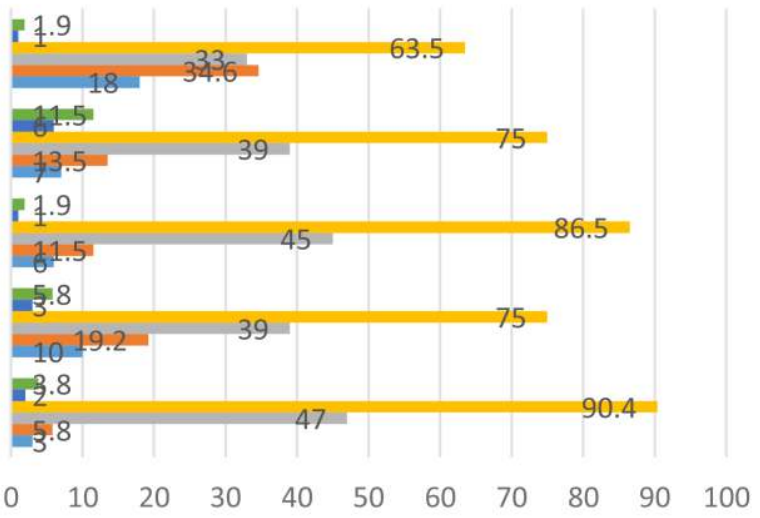

Above \%

Above F. At that level \%

At that level F. Below \% $\quad$ Below $\mathrm{F}$.

Figure II: Questions related to diagnosis and prognosis

\section{DISCUSSION}

Physical therapists are directly involved in assessment, diagnosis and treatment of various musculoskeletal and neurological conditions and that's the reason that competency of Physical therapist and Physical therapy interns are necessary. ${ }^{12}$ In recent years number of physical therapy institutes and physical therapy graduates have been enormously increased. ${ }^{13}$ In order to provide standard care to clients, it is necessary to determine competency of physical therapists and interns because they asses, diagnose and treat patients in clinical settings. ${ }^{14}$ However, there is limited literature available regarding assessment of competency of these clinicians in patients management skills. Therefore, current study was designed to report competency of physical therapy interns in patients management skills.

Results of the current study showed that almost all physical therapy interns were competent in patients management skills. The reason behind it can be the curriculum designed for physical therapy students in Pakistan by Higher Education Commission, Pakistan which is in line with international standards. Secondly, due to increasing awareness about physical therapy treatments in general population, physical therapy students are keen to learn clinical things with much priorities and therefore, the interns seem to have reasonable level of competencies in patients management skill. Thirdly, access to internet and introduction of evidence based physical therapy also helps in developing competency in patients management skill. Results of this study are in accordance with the 
study conducted in Saudi Arabia that found that overall physical therapy interns were competent in patients management skills. ${ }^{15}$ In the latter trial, few issues related to interns competencies were also identified, however, the over result favored that the included interns had reasonable level of competencies. In another study which was carried out on the levels of competencies in physical therapy interns, it was revealed that four areas needed further improvements in terms of competencies of the included interns. The areas which required improvement included background knowledge of the patients, skills in communication, documentation and the ability to manage the differences. ${ }^{16}$ The study's summative scores of the four major domains in the patients' management category showed that the PT interns' performance in the examination domain had the highest mean score compared with the other domains followed by the diagnosis/prognosis, intervention and evaluation domains with the percentages of 53.8, 21.2, 19.2 and 9.6, respectively. These results are contradicted to a study conducted in Saudi Arabia that concluded that evaluation was the domain with the highest mean score compared to other domains. This study pointed towards improvement in some areas that were found weaker compared to other areas in the interns. One of these areas is diagnosis/prognosis with a percentage of 57.7. This study is supported by a study conducted in 2013 in Saudi Arabia that found clinical examination, prognosis, diagnosis and intervention areas of improvements in the included interns. ${ }^{15}$

On a scale from 0 to 10 , the students compared to a competent clinician who is able to skillfully manage patients in an efficient manner to achieve effective patient/client outcome, about 44.2 percent of the respondents gave 4 out of 10 rating, 51.9 percent of them were awarded 5 number and 3.8 percent of them were awarded 6/10 number for their clinical competencies.

\section{CONCLUSIONS}

This study concluded that the physical therapy interns were competent in treating the patients and in providing quality care to the patients. These results were consistent with the training they get as part of their curriculum. However, the need for further improvements in some areas was highlighted. Further studies must find out the viewpoints of physical therapy interns and other stakeholders, including clients, providers, and healthcare systems. There were indications for the need of further improvement in certain competencies and skills such as clinical examination, evaluation, diagnosis and prognosis, and intervention.

\section{LIMITATIONS}

In this study, a limited number of interns was included therefore the results of this survey cannot be generalized to the all clinical interns working around the country.

\section{RECOMMENDATIONS}

It is recommended to conduct further studies with larger sample size of physical therapy interns. Moreover, Comparative studies can be conducted to find out the differences in clinical competencies of Pakistani physical therapy interns with physical therapy interns of other countries having same/similar qualification.

\section{REFERENCES}

1. Rathore FA, New PW, Iftikhar A. A report on disability and rehabilitation medicine in Pakistan: past, present, and future directions. Archives of physical medicine and rehabilitation. 2011; 92:161-6.

2. Khan F, Amatya B, Sayed TM, Butt AW, Jamil K, Iqbal W, et al. World Health Organization Global Disability Action Plan 2014-2021: Challenges and Perspectives for Physical Medicine and Rehabilitation in Pakistan. Journal of rehabilitation medicine. 2017; 49:10-21.

3. Association APT. Guide to Physical Therapist Practice. American Physical Therapy Association. Physical therapy. 2001; 81:9.

4. Childs JD, Whitman JM, Sizer PS, Pugia ML, Flynn TW, Delitto A. A description of physical therapists' knowledge in managing musculoskeletal conditions. BMC Musculoskeletal disorders. 2005; 6:32.

5. Morris TL, Hancock DR. Institute of Medicine core competencies as a foundation for nursing program evaluation. Nursing education perspectives. 2013; 34:29-33.

6. Therapy WCoP. WCPT guideline for physical therapist professional entry level education. 2017; Available from: https://www.wcpt.org/guidelines/entrylevel-education.

7. Taylor ML, Blue AV, Mainous III AG, Geesey ME, Basco Jr WT. The relationship between the National Board of Medical Examiners' prototype of the Step 2 clinical skills exam and interns' performance. Academic Medicine. 2005; 80:496-501.

8. Instruments TFftDoSCP, Instruments APTAsTFftDoSCP, Roach K, Gandy J, Deusinger SS, Clark S, et al. The development and testing of APTA clinical performance instruments. Physical Therapy. 2002; 82:329-53.

9. Fitzgerald LM, Delitto A, Irrgang JJ. Validation of the clinical internship evaluation tool. Physical therapy. 2007; 87:844-60.

10. eduvision. DPT Physiotherapy Universities and Colleges in Pakistan. 2017; Available $f \quad r \quad m$ m https://www.eduvision.edu.pk/institutionsoffering-physiotherapy-with-field-medicalsciences-at-bachelor-level-in-pakistanpage-1.

11. Commision HE. REVISED CURRICULUM. 2017 ; A v a i a b I e f rom : http://hec.gov.pk/english/services/universi
ties/RevisedCurricula/Pages/default.aspx 12. Salbach NM, Veinot $P$, Rappolt S, Bayley M, Burnett D, Judd M, et al. Physical therapists' experiences updating the clinical management of walking rehabilitation after stroke: a qualitative study. Physical therapy. 2009; 89:556-68.

13. Babur MN, Siddique FR, Awan WA. Future of physical therapy in Pakistan-Satisfaction amongst Pakistani physical therapists about their profession. Isra Medical Journal. 2014;6:25-7.

14. Gwyer J, Odom C, Gandy J. History of clinical education in physical therapy in the United States. Journal of Physical Therapy Education. 2003; 17:34.

15. BindawaS SM, Vennu V, Azer SA. Are physical therapy interns competent in patient management skills? Assessment of the views of clinical and academic physical therapists. Journal of physical therapy science. 2013; 25:649-55.

16. Dalton M, Davidson M, Keating JL. The assessment of physiotherapy practice (APP) is a reliable measure of professional competence of physiotherapy students: a reliability study. Journal of Physiotherapy. 2012; 58:49-56. 